\title{
Decadal changes in water temperature and ecological time series in Lake Geneva, Europe-relationship to subtropical Atlantic climate variability
}

\author{
Juan Carlos Molinero ${ }^{1, *}$, Orlane Anneville ${ }^{1}$, Sami Souissi $^{2}$, Leslie Lainé ${ }^{1}$, \\ Daniel Gerdeaux ${ }^{1}$
}

${ }^{1}$ Institut National de la Recherche Agronomique (INRA)-Station d'Hydrobiologie Lacustre, BP 511, 75 Avenue de Corzent, 74203 Thonon les Bains Cédex, France

${ }^{2}$ Université des Sciences et Technologies de Lille 1, CNRS-FRE 8, Ecosystèmes Littoraux Côtiers (ELICO), Station Marine, 28 Avenue Foch, 62930 Wimereux, France

\begin{abstract}
We investigated connections between subtropical Atlantic climate variability, atmospheric conditions in the European Alpine region ( 45 to $47^{\circ} \mathrm{N}$ and 5 to $8^{\circ} \mathrm{E}$ ) and the interannual variability of the thermal conditions in the largest body of freshwater in Western Europe (Lake Geneva). The long-term water temperature was related to climate variability by means of a multivariate regression model. Results revealed atmospheric connections that have been elusive so far, and showed that over the period from 1959 to 2000, summer thermal conditions in Lake Geneva appear tightly linked to the long-term variability of the subtropical Atlantic climate. The multivariate model revealed high skills and tight correlations, which suggest the possibility of assessing future thermal changes in Lake Geneva from the Atlantic climate variability. The implications of such climatic forcing on the functioning of the pelagic ecosystem in Lake Geneva were illustrated by analysing the long-term changes in abundance of the summer-dominant carnivorous cladocerans Bythotrephes longimanus and Leptodora kindtii during the period 1974 to 2000. Again, the multivariate model revealed high skills and excellent correlations between the interannual changes in abundance of these species and the variability of summer climate. Our approach provides a general understanding of the interrelations between large- and regional-scale climates, local environmental conditions and the ecological responses in Lake Geneva during summer, and is therefore applicable to other retrospective studies.
\end{abstract}

KEY WORDS: Subtropical Atlantic climate - Western Europe lakes · Temperature $\cdot$ Zooplankton · Leptodora kindtii $\cdot$ Bythotrephes longimanus

Resale or republication not permitted without written consent of the publisher

\section{INTRODUCTION}

Exploring the responses of aquatic ecosystems to climate change is a key area of global change ecology. Climate-related effects on the variability of physical and ecological features in limnic ecosystems have been widely documented (see Gerten \& Adrian 2002, Straile et al. 2003); however, few studies have so far been directed at the multiscale interactions between large-scale climate and local weather. In European lakes, most of the investigations into climate-driven changes have focused on the prevailing winter conditions, when atmospheric dynamics are most active and strongly affect climatic conditions in the North Atlantic and surrounding continents. In fact, during the boreal winter, atmospheric forcing of the North Atlantic represents the main form of physical forcing on aquatic ecosystems (i.e. through air temperature and wind), and the importance of the North Atlantic Oscillation (NAO) has been emphasised (Ottersen et al. 2001). The NAO corresponds to a large-scale meridional oscillation of atmospheric mass between the subtropical anti- 
cyclone near the Azores and the subpolar low pressure system near Iceland. Although the NAO signal is evident throughout the year, its signal strength is most pronounced during winter (Hurrell 1995). Subsequently, the statistical relationships between the NAO and ecological events have been documented from winter to early summer (Straile et al. 2003 and references therein). After this period, the NAO influence decreases, suggesting that different climatic phenomena may affect European lakes during summer.

A thorough understanding of the mechanistic basis underlying ecological responses to climate requires identification of the mediator factors linking largescale and local weather (Stenseth et al. 2003). The use of climate proxies at different scales of spatial resolution, as well as proper data treatment (i.e. statistical downscaling techniques), may help to bridge the gap between large-scale climate and local ecological responses (Müller-Navarra et al. 1997, Dippner et al. 2001, Pettorelli et al. 2005). In this study, we explored the influence of subtropical Atlantic climate forcing on the western Alpine region and long-term changes in water temperature in Lake Geneva. This is important because Lake Geneva represents the largest volume of freshwater in Western Europe, and further encompasses important commercial fish stocks such as whitefish, arctic char and perch. The sensitivity of the lake to winter climate forcing (i.e. NAO) has been previously investigated (Anneville et al. 2002, Molinero et al. 2006). However, to date, the climatic forcing governing the summer season remains unexplored.

Here we investigate climatic forcing during summer, a season in which strong connections between tropical climate variability and atmospheric fields in the EuroMediterranean area have been noted (Mariotti et al. 2005). On this basis, we used multi-decadal time series of climate and hydrology to explore the link between the subtropical Atlantic atmospheric variability and thermal conditions in Lake Geneva. Our aim was 2-fold: (1) to identify relationships between the subtropical Atlantic climate and summer water temperature in Lake Geneva; and (2) to investigate the potential ecological implications of such climatic forcing and analyze the interannual variability of the summer-dominant carnivorous cladocerans Leptodora kindtii and Bythotrephes longimanus. In comparison with the spring-dominant phytoplanktivorous cladocerans (e.g. Daphnia spp.), which have been quite thoroughly investigated, little attention has been directed to the former species. Understanding how climate affects large-bodied carnivorous species is important because these species act as main predators of zooplankton (i.e. small cladocerans and copepods) and are the selected targets of fish (e.g. whitefish). Moreover, they express markedly different life-history traits, which allows the investigation of climate effects on different lifehistories within the same trophic group.

\section{DATA AND STATISTICAL APPROACH}

\subsection{Physical and biological data}

Owing to the influence from mid-latitudes on the climatology of Western Europe (Dünkeloh \& Jacobeit 2003, Rimbu et al. 2004, Wu \& Hsieh 2004, Mariotti et al. 2005), we used key modes of atmospheric variability that act over the subtropical Atlantic sector to assess large-scale climate forcing on the Alpine region; i.e. the Atlantic Multidecadal Oscillation (AMO), El Niño Southern Oscillation (ENSO), Tropical North Atlantic Index (TNA) and East Atlantic Pattern (EA). The longterm variability of atmospheric conditions in the Alpine region ( 45 to $47^{\circ} \mathrm{N}$ and 5 to $8^{\circ} \mathrm{E}$ ) was assessed using monthly anomaly fields of air temperature, humidity, atmospheric pressure, $500 \mathrm{hPa}$ geopotential height and precipitation records for the period 1950 to 2000 from the Climate Diagnostics Center (NCEP/NCAR) reanalysis fields (Kalney et al. 1996). The season analyzed extended from June to September (JJAS). In terms of hydrological data, we used monthly records of summer water temperature (JJAS) in Lake Geneva. This time series spans from 1959 to 2000, and the data used corresponded to the mean temperature in the 0 to $50 \mathrm{~m}$ depth layer.

To explore the potential effects of the subtropical Atlantic climate on pelagic populations, we investigated the long-term abundance of the summerdominant carnivorous cladocerans Leptodora kindtii and Bythotrephes longimanus. These samples were collected within the framework of the program of the International Commission for the Protection of Lake Geneva (CIPEL). The sampling protocol consisted of vertical hauls in the first $50 \mathrm{~m}$ with a plankton net of $200 \mu \mathrm{m}$ mesh-size. The sampling frequency was fortnightly or monthly over the whole year, and the period covered spanned from 1974 to 2000.

\subsection{Statistical analysis}

Data were averaged at a monthly frequency and then standardised at zero mean and unit variation. The approach used is based on the statistical downscaling model of von Storch et al. (1993) and von Storch (1995), who used a multivariate model to explore correlations between the regional/local observations of interest and potentially important climate variables operating at larger scales. This approach has been previously applied to investigate climate effects on terrestrial 
(Maak \& von Storch 1997, Matulla et al. 2003) and aquatic (Heyen et al. 1998, Dippner \& Ottersen 2001, Dippner et al. 2001) ecosystems.

\subsubsection{Model fitting}

First, we evaluated the interrelations between the subtropical Atlantic climate modes and regional atmospheric variability. The connections between the 2 climatic signals operating at large and regional scales (i.e. subtropical climatic modes and atmospheric variables of the Alpine region) were investigated by means of Pearson product-moment correlations between the leading eigenmodes (3 principal components, PCs) of large (subtropical Atlantic) and regional (Alpine region) climate, which condensed most of the variability of such data sets (see Table 1). Then, the variables responsible for the link (i.e. those showing the highest skills) were selected to build up the downscaling model. For each chosen combination of predictor (climate) and predictand (i.e. water temperature), the model was built in the following way: PCs of the predictor were calculated to reduce the number of parameters of the model, and Principal Component Analysis (PCA) was used to extract the main climatic signal. PCA was then applied on a matrix $Z$ comprised of an ensemble of variables: i.e. years $\times$ climatic variables (subtropical climatic modes and regional atmospheric variables). PCA axes are orthogonal and therefore independent of one another. This allowed the creation of composite independent climate variables and thus avoided the spurious correlations inherent in a multivariate design with non-orthogonal climate factors (Voigt et al. 2003). Then, Canonical Correspondence Analysis (CCA) was performed between the leading PCs of climate (predictor) and water temperature (predictand). This allowed the identification of the connection between subtropical Atlantic climate and water temperature in Lake Geneva. To build a model using the same set of variables, several combinations with different lags between climate modes and regional atmospheric factors were evaluated. A conservative $\alpha$-level of 0.01 was used to minimize the likelihood of committing a Type I error when identifying links between climate and water temperature. The same procedure was used to build up the model for zooplankton.

\subsubsection{Validation of the model and skill factor}

Because CCA correlations are optimized with respect to the data considered, a validation of the correlation is required. In accordance with Dippner et al. (2001), we used a cross-validation technique (Michaelsen 1987) in combination with Monte Carlo simulations to validate our model. In the crossvalidation, if $n$ time steps of data are available, then $n$ models are fitted by using $n-1$ time steps each. For each model, the $n$th step of the predictand is regressed from the predictor. Finally, the $n$ estimations are compared with the observations of the predictand. For the cross-validation, all data were used and no data were discarded.

From all combinations tested, the results with the highest skills were selected. The coefficient $r$ (that between the regional observations and cross-validated estimations) and Brier-based score $\beta$ were used as skill factors. The Brier-based score is defined as $\beta=$ $1-\left(\sigma_{\mathrm{e}}^{2} / \sigma^{2}{ }_{\mathrm{o}}\right)$, where $\sigma_{\mathrm{e}}^{2}$ and $\sigma^{2}{ }_{\mathrm{o}}$ are the variances of the errors (i.e. observation minus model) and observations respectively. A score of $\beta=1$ means that the model and observation are identical, whereas $\beta=0$ means that the error of the model has the same size as the variance of the observations (Livezey 1995).

\section{RESULTS}

PC1 of the subtropical Atlantic climate (59\% of total variance) encapsulates the low frequency variability of the Atlantic sea surface temperature, namely the TNA and the AMO. The variability of climate in the Alpine region during summer shows a similar pattern, for which PC1 ( $60 \%$ of variance) highlighted the variability of $500 \mathrm{hPa}$ geopotential height, air atmospheric temperature and surface pressures. PC2 of the subtropical Atlantic climate (31\% of variance) primarily represented the ENSO variability, whereas PC2 of the summer Alpine climate (19\% of variance) captured the variability of the surface atmospheric pressure. PC3 of the subtropical Atlantic climate ( $8 \%$ of variance) summarized the EA pattern, whereas PC3 in the Alpine region (17\% of variance) accounted for the long-term pattern of precipitation (Table 1). In Fig. 1, we show the main pattern (PC1) of subtropical Atlantic and Alpine climates. The long-term variability of these climatic signals reveals remarkably similar patterns during the period from 1950 to 2000. Pearson's correlation coefficient and the effective probability after correction for temporal autocorrelation are $\mathrm{r}=0.50$ and $\mathrm{p}<0.001$ respectively. In Table 2 we present the correlation coefficients of climatic modes and atmospheric factors in the Alpine region during the summer period. Most of the correlations, including that of water temperature, indicate a positive response of the regional atmospheric variability to the subtropical Atlantic influence.

Accordingly, CCA reveals highly significant links between climate variability during summer (as predic- 
Table 1. Percentage of total variance associated with the 3 principal components (PCs) of large-scale and regional climates. The contribution of climatic and atmospheric factors to the formation of each PC is also given. EA: East Atlantic Pattern; TNA: Tropical North Atlantic pattern; AMO: Atlantic Multidecadal Oscillation; ENSO: El Niño Southern Oscillation

\begin{tabular}{|lccc|}
\hline Climate scale & PC1 & PC2 & PC3 \\
\hline Large-scale (subtropical Atlantic) & & & \\
Variance (\%) & 59 & 31 & 8 \\
EA & -0.53 & 0.43 & -0.72 \\
TNA & 0.88 & -0.22 & 0.24 \\
AMO & 0.89 & -0.36 & 0.04 \\
ENSO & -0.35 & 0.81 & 0.40 \\
Regional (Alpine; summer, JJAS) & & & \\
Variance (\%) & 60 & 19 & 17 \\
Humidity & 0.48 & 0.17 & 0.86 \\
500 hPa geopotential height & 0.96 & -0.26 & -0.04 \\
Air temperature & 0.85 & 0.47 & -0.20 \\
Atmospheric pressure & 0.83 & -0.67 & -0.04 \\
\hline
\end{tabular}

tand) and the interannual variability of water temperature in the $50 \mathrm{~m}$ upper layer over the period 1959 to 2000. As climate predictors of water temperature, we used subtropical Atlantic climate modes such as AMO, TNA and EA and regional atmospheric variability in the Alpine region (air temperature, humidity, $500 \mathrm{hPa}$ geopotential height). The results of the downscaling model for water temperature are given in Table 3 . The downscaling model reveals that the summer water temperature anomalies in Lake Geneva are highly sensitive to climatic signals operating at large and regional scales (Fig. 2). Moreover, when considering a model built using only the climatic modes of the subtropical Atlantic sector (i.e. AMO, TNA, EA), significant CCA correlations again exist between such climate variability and summer water temperature (Table 3).

Furthermore, CCA reveals significant relationships between climate and the 2 species of carnivorous cladocerans. The downscaling model shows that the interannual abundance variabilities of Leptodora kindtii and Bythotrephes longimanus are highly significantly correlated to the climatic anomalies in the subtropical Atlantic sector (Table 3, Fig. 3). We used the subtropical Atlantic climate modes, regional atmospheric variability in the Alpine region (air temperature, humidity, $500 \mathrm{hPa}$ geopotential height) and water temperature as climate predictors of the abundances of $L$. kindtii and $B$. longimanus. Yet again, the correlations found remained significant when using only the climatic modes of the subtropical Atlantic sector to build up the model, as shown by the results of $\mathrm{CCA}_{i} \mathrm{r}=0.53$ (climate and Leptodora kindtii) and $\mathrm{r}=0.63$ (climate \& Bythotrephes longimanus). The correlations displayed are significant with respect to the $99 \%$ confidence level.

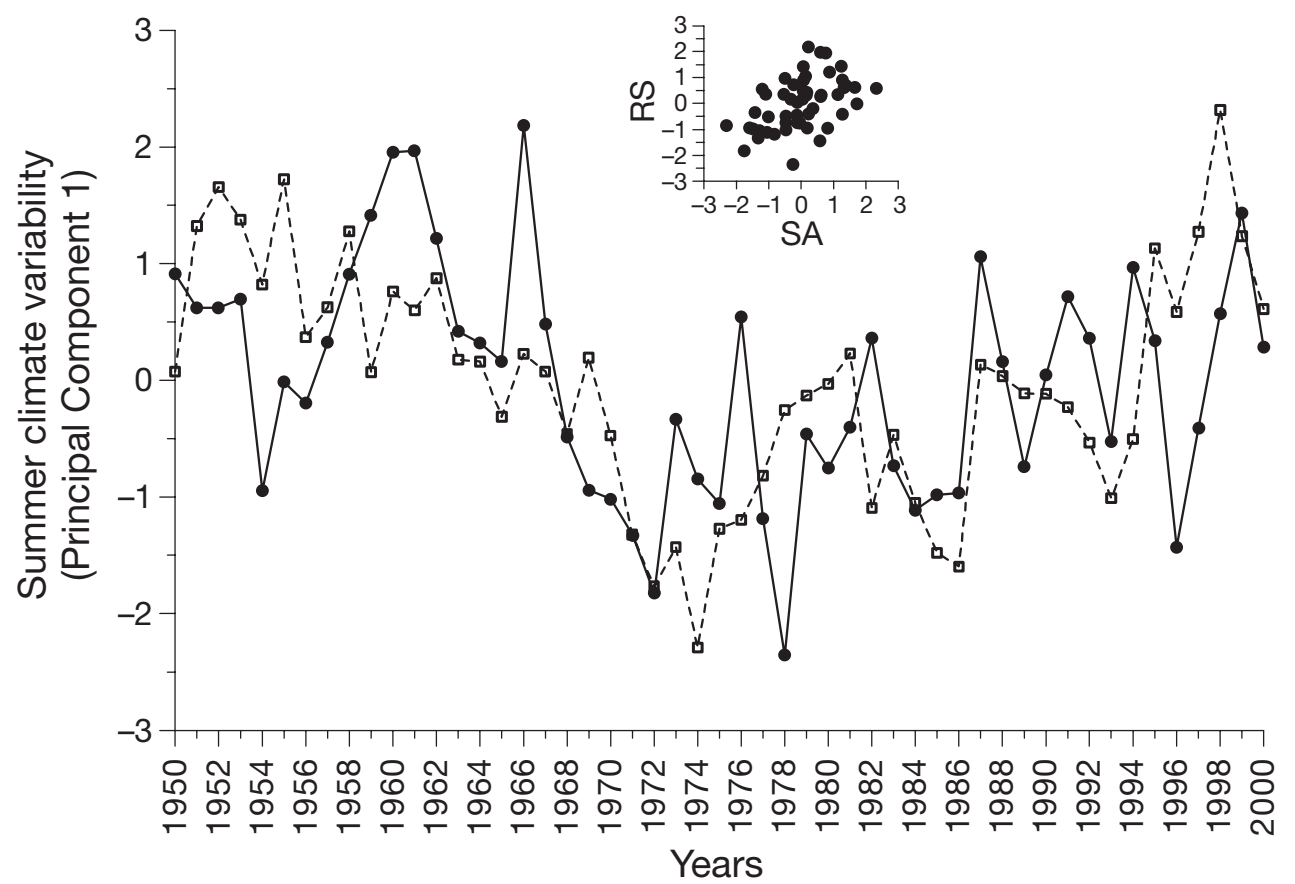

Fig. 1. Main pattern (PC1s) of inter-annual variability of the subtropical Atlantic climate (口) and summer atmospheric variability of the western Alpine climate $(\bullet)\left(45-47^{\circ} \mathrm{N}, 5-8^{\circ} \mathrm{E}\right)$ during $1950-2000$. The dispersion diagram of the relationship between the Alpine (RS) and subtropical Atlantic (SA) climates is also shown (inset). Values are expressed as anomalies (standard deviations from the mean of the time series). Pearson's correlation coefficient and effective probability after correction for temporal autocorrelation are $\mathrm{r}=0.50$ and $\mathrm{p}<0.001$ 
Table 2. Cross-correlation coefficients for large-scale climatic modes and regional atmospheric factors in the Alpine region. Significant correlations indicated in bold. Effective probability after correction for temporal autocorrelation: ${ }^{*} p<0.01 ;{ }^{* *} p<0.005$. EA: East Atlantic Pattern; TNA: Tropical North Atlantic pattern; AMO: Atlantic Multidecadal Oscillation; ENSO: El Niño Southern Oscillation; 500 hPa: geopotential height

\begin{tabular}{|c|c|c|c|c|c|c|c|c|}
\hline & EA & TNA & ENSO & $\mathrm{AMO}$ & Air temp & $500 \mathrm{hPa}$ & Humidity & Water temp \\
\hline EA & 1 & & & & & & & \\
\hline TNA & 0.25 & 1 & & & & & & \\
\hline ENSO & 0.17 & 0.20 & 1 & & & & & \\
\hline $\mathrm{AMO}$ & $0.42^{*}$ & $0.82^{*}$ & 0.02 & 1 & & & & \\
\hline Air temp & $0.41^{*}$ & -0.01 & 0.08 & $0.39^{* *}$ & 1 & & & \\
\hline $500 \mathrm{hPa}$ & $0.50^{*}$ & -0.07 & 0.10 & 0.16 & $0.64^{*}$ & 1 & & \\
\hline Humidity & 0.01 & 0.05 & -0.03 & $-0.33^{* *}$ & $-0.49^{*}$ & -0.16 & 1 & \\
\hline Water temp & 0.22 & $0.32^{* *}$ & 0.05 & $0.59^{*}$ & $0.62^{*}$ & 0.08 & $-0.57^{*}$ & 1 \\
\hline
\end{tabular}

Table 3. Results of downscaling models. Predictors and predictands are given, as are $99 \%$ CI of CCA coefficients (CCA), the correlation coefficients after cross-validation (CC) and the skill model (Brier-based score, $\beta$ ). The predictor Climate 1 encompasses the leading 3 PCs of large-scale climatic modes (EA, TNA, AMO; see Table 2 for definitions) and alpine atmospheric variables (humidity, air temperature, $500 \mathrm{hPa}$ geopotential height). The predictor Climate $1 \mathrm{~b}$ encompasses the leading $3 \mathrm{PCs}$ of the large-scale climatic modes (EA, TNA, AMO). The predictor Climate 2 encompasses the leading 3 PCs of large-scale climatic modes, alpine atmospheric variables and water temperature

\begin{tabular}{|llccc|}
\hline Predictor & Predictand & CCA & CC & $\beta$ \\
\hline Climate 1 & Water temperature & 0.85 & 0.80 & 0.65 \\
Climate 1b & Water temperature & 0.67 & 0.63 & 0.54 \\
Climate 2 & Leptodora kindtii & 0.70 & 0.65 & 0.37 \\
Climate 1b & Leptodora kindtii & 0.55 & 0.50 & 0.70 \\
Climate 2 & Bythotrephes longimanus & 0.71 & 0.66 & 0.41 \\
Climate 1b & Bythotrephes longimanus & 0.63 & 0.60 & 0.60 \\
\hline
\end{tabular}

\section{DISCUSSION}

\subsection{Subtropical Atlantic climate and water temperature}

CCA allowed us to identify the interrelation between the climate regimes of the subtropical Atlantic sector and in the western Alpine region; the control of these regimes on thermal conditions in Lake Geneva, and ultimately, their effects on the inter-annual variability of the summer-dominant carnivorous caldocerans Leptodora kindtii and Bythotrephes longimanus. Investigations of climatic impacts on aquatic and terrestrial ecosystems in the Alpine region, and more generally on western European lakes, have mainly focused on the influence of the North Atlantic sector (Quadrelli et al. 2001, Beniston \& Jungo 2002, Trigo et al. 2002). Accordingly, the influence of the NAO on the study region has been extensively documented (Straile et al.
2003 and references therein). Together with previous investigations (Mariotti et al. 2002, 2005), here we provide evidence of the summertime link between the Alpine region and subtropical Atlantic climate forcing. Subsequently, such interrelationship favours the subtropical climatic signatures on the thermal conditions of the largest body of freshwater in Western Europe. Winter teleconnection has been explained by the advection of heat flow and moisture transport, which are associated with the strength of westerlies and the Atlantic storm track pattern (Quadrelli et al. 2001, Trigo et al. 2002). Fernandez et al. (2003) analyzed 2 different instrumental data sets of precipitation over the Mediterranean and southern Europe, and identified sources of moisture transport over these regions. They demonstrated that the main pattern of moisture transport and precipitation has its roots in the dynamics of the Atlantic storm track. Similar findings were presented by Beniston \& Jungo (2002), who demonstrated that higher than normal atmospheric pressure over the Azores allows enhanced temperature and atmospheric pressure fields, to affect moisture transport in the Alpine region. During summer, the subtropical high intensifies and fewer Atlantic storms impact the Euro-Mediterranean region; hence, the connection with tropical regions becomes more important (Mariotti et al. 2005).

In summer, the air temperature, humidity and atmospheric pressure fields appeared to be significantly related to the subtropical Atlantic signal (see Table 1). This suggests a mediating role in heat flow and moisture transport, which affect regional air temperature, humidity and subsequently air-water exchanges. We suggest that the connection pathway controls thermal conditions in Lake Geneva, as shown by the high correlations between summer water temperature records and climate forcing. Furthermore, the subtropical Atlantic climate appears useful for evaluating regional climate variability in the Alpine region because it 


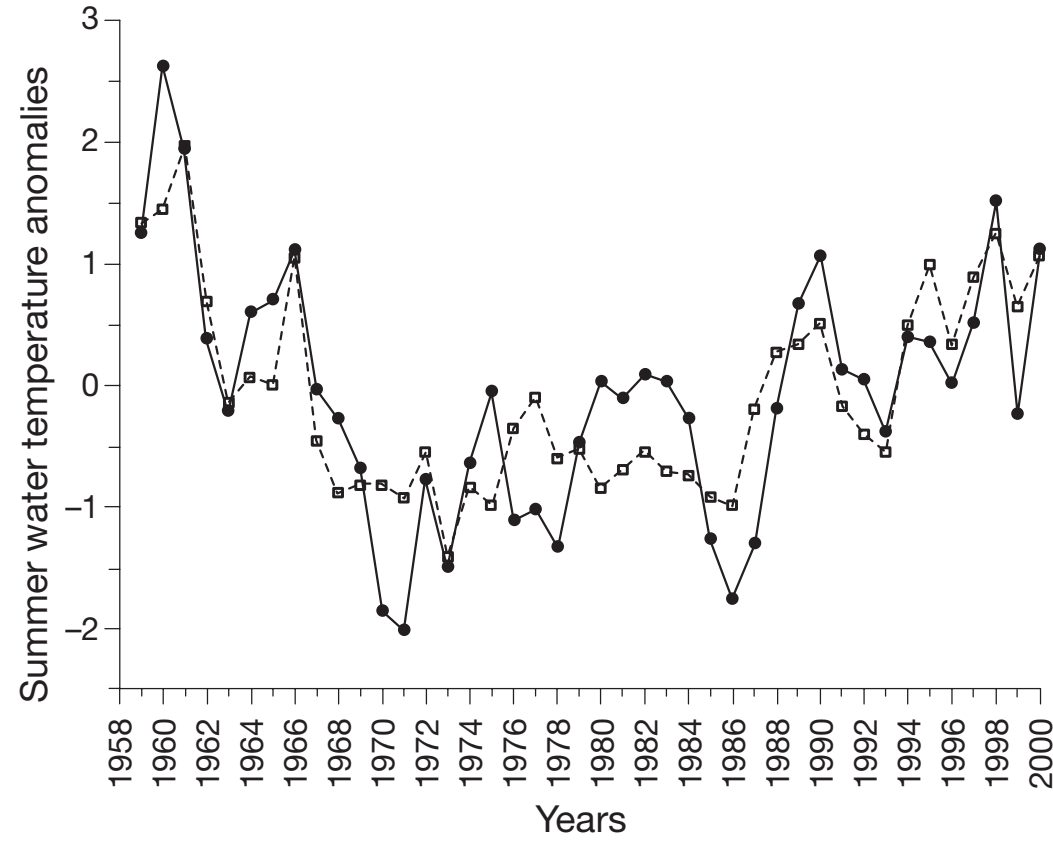

Fig. 2. Anomalies (standard deviations from the mean of the time series) in observed annual mean summer (JJAS) water temperature (•) and those predicted from the leading 3 PCs of large-scale and regional climate signals ( $\square$ ) during 1959-2000. Correlation of cross-validation is 0.80 ; model skill $(\beta)$ is 0.65

encompasses spatial and temporal fields of atmospheric forcing affecting Western Europe (Mariotti et al. 2002, Dünkeloh \& Jacobeit 2003, Rimbu et al. 2004). Indeed, because climatic indices integrate the variability of several weather components, they appear to be excellent tools with which to evaluate regional environmental changes and assess large-scale climate and local weather interactions (Stenseth et al. 2003). The approach used here allowed us to demonstrate that summer thermal conditions in Lake Geneva are sensitive to the subtropical Atlantic climate; a relationship that has been elusive so far. Such climatic forcing may also affect other western European lakes, which strongly suggests that the seasonal variability of climatic forcing on European lakes has its roots in different sectors of the Atlantic Ocean: the winter-spring period is dominated by North Atlantic climate forcing (Livingstone \& Dokulil 2001, Gerten \& Adrian 2002, Straile et al. 2003, Adrian et al. 2006, Molinero et al. 2006), and the summer is dominated by subtropical Atlantic climate forcing.

In the European alpine region, climate forcing on limnic ecosystems is complex and may vary with the altitudinal gradient. In fact, the topographic characteristics of this zone may lead to a differential effect over the aquatic ecosystems (Livingstone et al. 1999, 2005). Livingstone et al. (2005) showed that in the European alpine lakes, the relationship between water temperature and surface air temperature varies with altitude.
Their results identified 2 thermal regimes, of which the low-altitude regime appeared more sensitive to air temperature changes. Accordingly, in Lake Geneva (situated within the low altitude regime), we found high correlation coefficients between air and water temperatures ( $\mathrm{r}=$ 0.60; $\mathrm{p}<0.01$ ). Therefore, air temperature may be a pivotal factor that links regional and large-scale mechanisms with water temperature (Straile et al. 2003 and references therein). In fact, air temperature is explicitly involved in the exchange processes that affect surface water temperature in lakes. Hence, the role it plays in surface water temperature variability, as well as in the sensitivity of surface water temperature to large-scale atmospheric variability, allows climatic signals to be reflected in lake temperature, as has been noted in other European aquatic ecosystems (Straile et al. 2003, Dokulil et al. 2006, Hari et al. 2006). In turn, the ecological implications of the subtropical climatic signatures in Lake Geneva are supported by the tight link between climate and the long-term changes in abundance of the summer-dominant carnivorous cladocerans Leptodora kindtii and Bythotrephes longimanus.

During recent decades, European lakes have experienced warming conditions that favoured thermal stability, a lengthening of the stratification period and a longer period of homothermy (Livingstone \& Dokulil 2001, Livingstone 2003). On the European scale, several studies have shown a high degree of regional coherence in the thermal properties of lakes (Livingstone \& Lotter 1998, Livingstone \& Dukulil 2001, Straile et al. 2003, Livingstone et al. 2005, Dokulil et al. 2006). This is likely to be because the mediator factors (i.e. heat flow, moisture transport, air temperature) are driven by regionally coherent atmospheric fields that favour a common climatic signal over regional scales. Therefore, it is plausible that the subtropical Atlantic climate forcing observed in the thermal conditions of Lake Geneva also affect other western European lakes, as suggested by the regional atmospheric control on the suggested mediator factors (i.e. air and water temperature, humidity and atmospheric pressure fields).

\subsection{Ecological responses to summer climate forcing}

Numerous studies have shown drastic changes in the pelagic phenology of limnic ecosystems, which may have ramifications for trophic interactions, alter food- 

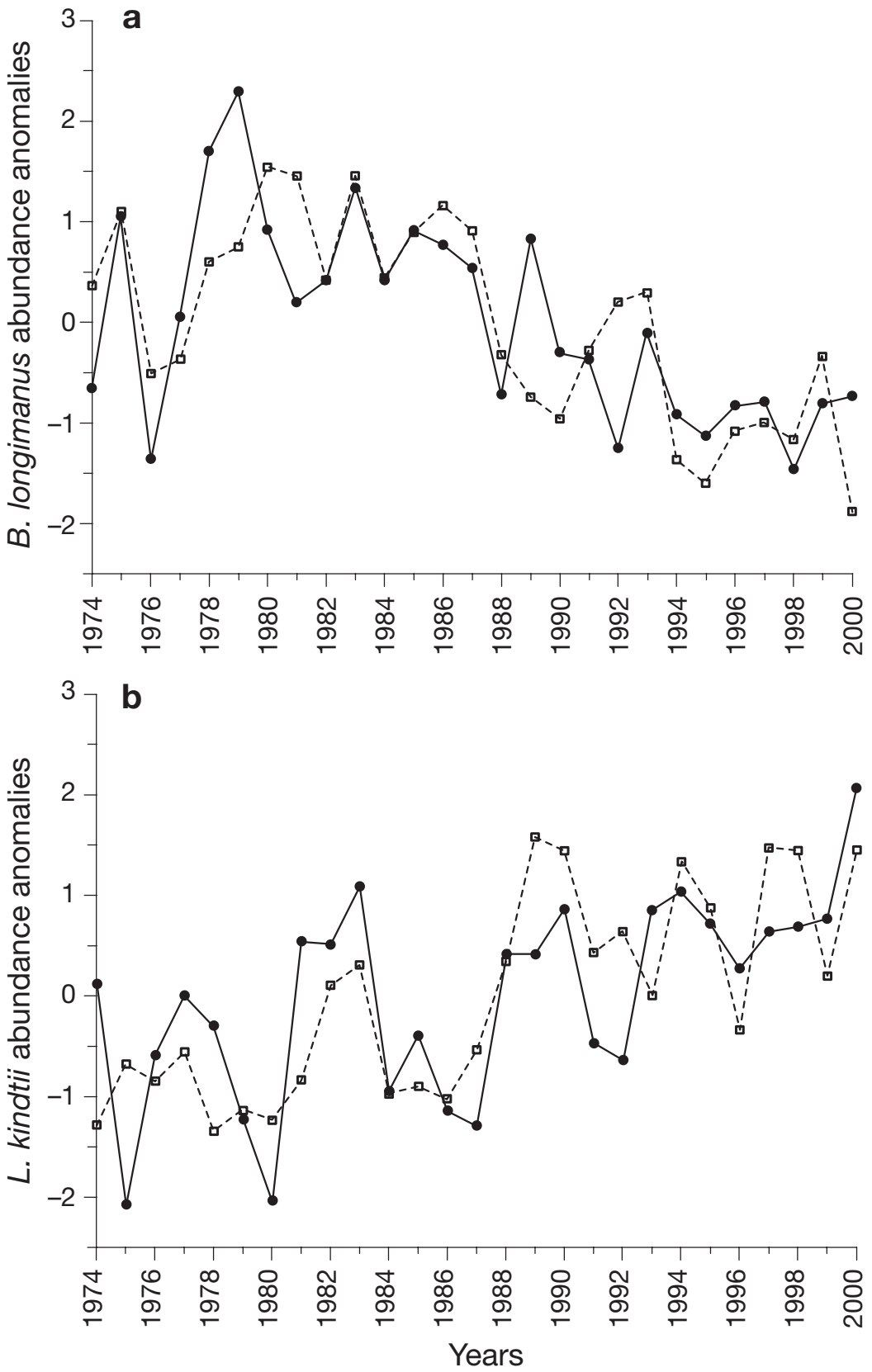

Fig. 3. Bythotrephes longimanus and Leptodora kindtii. Anomalies (standard deviations from the mean of the time series) in observed annual mean summer (JJAS) abundances (•) of (a) B. longimanus and (b) L. kindtii and those predicted from the leading 3 PCs of large-scale and regional climate signals and water temperature () during 1974-2000. Correlation of crossvalidation and model skill $(\beta)$ is 0.66 and 0.41 for $B$. longimanus; and 0.65 and 0.37 for $L$. kindtii respectively

web structures and lead to eventual ecosystem-level changes (Straile et al. 2003, Winder \& Schindler 2004, Adrian et al. 2006). Our results revealed that the longterm abundance variations in the carnivorous cladocerans Leptodora kindtii and Bythotrephes longimanus are linked to large-scale climatic forcing, and particularly to the summer variability of such climate signals.
However, the observed changes in the abundance of these species are opposed: while $L$. kindtii appears to be favored by the long-term environmental changes (i.e. warmer water temperature), the same environmental forcing seems to have impaired the abundance of $B$. longimanus. The analysis of the life-history traits of these species can provide a mechanistic basis for understanding the long-term changes in the abundance of the investigated species. The average clutch size of $L$. kindtii is generally larger than that observed in $B$. longimanus (Branstrator 2005). Maximum L. kindtii clutch sizes can reach between 20 to 24 eggs per clutch (Lake Tjeukemeer and Lake Erie, respectively) (Vijverberg et al. 2005), whereas B. longimanus maximum clutch sizes range from 10 to 12 eggs per clutch (Sullivan \& Lehman 1998, Straile \& Hälbich 2000). Moreover, as in other cladoceran species (i.e. Daphnia spp.), the developmental time and age to sexual maturation appear to be temperaturedependent (Branstrator 2005 and references therein). Thus, a plausible ecological explanation must stress that warming conditions may affect the biological rates of the 2 species and lead to changes in their population size. However, the imbalance between the 2 species may be explained by parallel climate-related ecological changes that have occurred in Lake Geneva, such as a decrease in large Daphnia species, and the high abundances of both small-bodied cladocerans (i.e. Bosmina spp.) and whitefish (O. Anneville et al. unpubl. data); however, we cannot exclude a link between all these ecological modifications and changes in nutrient loadings in Lake Geneva (O. Anneville et al. unpubl. data). Compelling evidence has shown that a substantial decrease in large-bodied Daphnia spp., the main prey of B. longimanus, can impair the latter's population size (Branstrator 2005 and references therein). Thus, it is suggested that the combined effect of these factors (i.e. the increase in predation pressure and the decrease in the main food item) has been a significant selective force shaping local fitness of $B$. longimanus. Subsequently, owing to potentially smaller starting population densities, the potentially lower abundance of $B$. longimanus may be reflected in future generations. Modelling studies have shown that relatively few variations (i.e. 
lower/higher than normal starting individuals) could greatly impair/enhance the development of zooplankton crustacean populations (Souissi et al. 2004).

Regarding Leptodora kindtii's long-term changes, it is plausible that its high abundance since the 1980s has been favored by the high abundance of small-bodied cladocerans in Lake Geneva (i.e. Bosmina spp.), which appear to be optimally sized prey for this group (Branstrator \& Lehman 1991, Branstrator 1998). In addition, L. kindtii generates large numbers of smallbodied offspring when visually discriminating predators (i.e. planktivorous fish) are abundant (Branstrator 2005), as has also been the case in Lake Geneva since the 1980s (O. Anneville unpubl. data). Thus, it is plausible that a potential shortening in the life-history preceding adulthood, as suggested by rising temperatures and temperature-dependent development, has allowed $L$. kindtii to maximize its individual fitness per offspring: survival is aided by small body size and the availability of optimally sized prey, as well as by the potentially larger starting population density, which can be reflected in following generations. In turn, longterm changes in the abundance of $L$. kindtii may have an important effect on pelagic zooplankton because it can consume up to $50 \%$ of cladoceran production during summer, which allows $L$. kindtii to be one of the main channels of energy flux to upper trophic levels (Branstrator 2005). Of course, anthropogenic effects (i.e. phosphorus reduction) on the 2 carnivorous cladocerans cannot be excluded; however, our results show that at least a substantial component of their long-term changes in abundance appears to be driven by the summer warming in Lake Geneva, which is ultimately linked to the subtropical Atlantic climate.

\section{CONCLUDING REMARKS}

The method used in this study allowed us to quantify the degree of correlation between climatic signals operating in the subtropical Atlantic and the Alpine region with thermal conditions in Lake Geneva. An examination of these results highlights atmospheric connections that have been elusive so far, and shows that over the period 1959 to 2000, the summer thermal conditions in Lake Geneva can be modelled by considering the subtropical Atlantic climate. We also stress the role that water temperature plays in the limnic eco-system as a mediator factor linking large-scale climate with local ecological processes. The ecological implications of the summer warming are illustrated by the long-term changes in abundance of the summerdominant carnivorous cladoceran. By using climate proxies relative to different spatial scales and thermal conditions in Lake Geneva, we provide a general understanding of the effects of climate on local weather and ecological responses in the European Alps during summer. The approach we used is applicable to other retrospective studies to assess climatic effects on European lakes. We further stress that a complete understanding of the effects of climatic forcing on these ecosystems requires an identification of the sources of climate forcing that can affect the variability of European lakes.

Acknowledgements. We are indebted to many people who contributed to the long-term data set of Lake Geneva, and to the International Committee for the Protection of the Water of Lake Geneva (CIPEL), the French Ministry of Environment, and GIP Hydro-Systèmes for funding. J.C.M. was funded by INRA within the framework of the 'Detection of Climate Effects on Zooplankton Communities and their Consequences on Fisheries (P23)' project. NCEP Reanalysis data were provided by the NOAA-CIRES ESRL/PSD Climate Diagnostics branch (available at www.cdc.noaa.gov); we thank Cathy Smith for maintaining the Reanalysis climate data. We also thank the Climatic Research Unit (CRU) and the Climatic Prediction Center of NOAA for making climatic indices available.

\section{LITERATURE CITED}

Adrian R, Wilhelm S, Gerten D (2006) Life-history traits of lake plankton species may govern their phenological response to climate warming. Global Change Biol 12:1-10

Anneville O, Souissi S, Ibanez F, Ginot V, Angeli N (2002) Temporal mapping of phytoplankton assemblages in Lake Geneva: annual and interannual changes in their patterns of succession. Limnol Oceanogr 47:1355-1366

Beniston M, Jungo P (2002) Shifts in the distribution of pressure, temperature and moisture and changes in the typical weather patterns in the Alpine region in response to the behavior of the North Atlantic Oscillation. Theor Appl Climatol 71:29-42

Branstrator DK (1998) Predicting diet composition from body length in the zooplankton predator Leptodora kindtii. Limnol Oceanogr 43:530-535

Branstrator DK (2005) Contrasting life-histories of the predatory cladoceran Leptodora kindtii and Bythotrephes longimanus. J Plankton Res 27:569-585

Branstrator DK, Lehman JT (1991) Invertebrate predation in Lake Michigan: regulation of Bosmina longirostris by Leptodora kindtii. Limnol Oceanogr 36:483-495

Dippner J, Ottersen G (2001) Cod and climate variability in the Barents Sea. Clim Res 17:73-82

Dippner J, Hänninen J, Kuosa H, Vuorinen I (2001) The influence of climate variability on zooplankton in the Northern Baltic Archipelago Sea (SW Finland). ICES J Mar Sci 58: 569-578

Dokulil M, Jagsch A, George G, Anneville O and 5 others (2006) Twenty years of spatially coherent deep-water warming in lakes across Europe related to the North Atlantic Oscillation. Limnol Oceanogr 51:2787-2793

Dünkeloh A, Jacobeit J (2003) Circulation dynamics of the Mediterranean precipitation variability 1948-1998. Int J Climatol 23:1843-1866

Fernandez J, Saenz J, Zorita E (2003) Analysis of wintertime atmospheric moisture transport and its variability over 
southern Europe in the NCEP Reanalyses. Clim Res 23: $195-215$

Gerten D, Adrian R (2002) Effects of climate warming, North Atlantic Oscillation, and El Niño-Southern Oscillation on thermal conditions and plankton dynamics in Northern Hemispheric Lakes. Sci World 2:586-606

Hari R, Livingstone D, Siber R, Bukhardt-Holm P, Güttinger H (2006) Consequences of climatic change for water temperature and brown trout populations in Alpine rivers and streams. Global Change Biol 12:10-26

Heyen H, Fock H, Greve W (1998) Detecting relationships between the interannual variability in ecological time series and climate using a multivariate statistical approach - a case study on Helgoland Roads zooplankton. Clim Res 10:179-191

Hurrell JW (1995) Decadal trends in the North Atlantic Oscillation: regional temperature and precipitation. Science 269:676-679

Kalney E, Kanamitsu M, Kistler R, Collins W and 18 others (1996) The NCEP/NCAR 40-year reanalysis project. Bull Am Meteorol Soc 77:437-471

Livezey RE (1995) The evaluation of forecasts. In: von Storch $\mathrm{H}$, Navarra A (eds) Analysis of climate variability. SpringerVerlag, Berlin, p 177-196

Livingstone DM (2003) Impact of secular climate change on the thermal structure of a large temperate central European lake. Clim Change 57:205-225

Livingstone DM, Dokulil MT (2001) Eighty years of spatially coherent Austrian lake surface temperatures and their relationship to regional air temperature and the North Atlantic Oscillation. Limnol Oceanogr 46:1220-1227

Livingstone DM, Lotter AF (1998) The relationship between air and water temperatures in lakes of the Swiss Plateau: a case study with paleolimnological implications. J Paleolimnol 19:181-198

Livingstone DM, Lotter AF, Walker IR (1999) The decrease in summer surface water temperature with altitude in Swiss Alpine lakes: a comparison with air temperature lapse rates. Arct Antarct Alp Res 31:341-352

Livingstone DM, Lotter AF, Kettle H (2005) Altitude-dependent differences in the primary physical response of mountain lakes to climatic forcing. Limnol Oceanogr 50:1313-1325

Maak K, von Storch H (1997) Statistical downscaling of monthly mean air temperature to the beginning of flowering of Galanthus nivalis L. in Northern Germany. Int J Biometeorol 41:5-12

Mariotti A, Zeng N, Lau KM (2002) Euro-Mediterranean rainfall and ENSO - seasonally varying relationship. Geophys Res Lett 12:1621, doi: 10.1029/2001GL014248

Mariotti A, Ballabrera-Por J, Zeng N (2005) Tropical influence on Euro-Asian autumn rainfall variability. Clim Dyn 24: 511-521

Matulla C, Scheifinger H, Menzel A, Koch E (2003) Exploring two methods for statistical downscaling of Central European phenological time-series. Int J Biometeorol 48:56-64

Michaelsen J (1987) Cross-validation in statistical climate forecast models. J Clim Appl Meteorol 26:1589-1600

Molinero JC, Anneville O, Souissi S, Balvay G, Gerdeaux D (2006) Anthropogenic and climatic forcing on the longterm changes of planktonic rotifers in Lake Geneva, Europe. J Plankton Res 28:287-296

Müller-Navarra D, Güs S, von Storch H (1997) Interannual variability of seasonal succession events in a temperate

Editorial responsibility: Geir Ottersen, Oslo, Norway lake and its relation to temperature variability. Global Change Biol 3:429-438

Ottersen G, Planque B, Belgrano A, Post E, Reid C, Stenseth N (2001) Ecological effects of the North Atlantic Oscillation. Oecologia 128:1-14

Pettorelli N, Mysterud A, Yoccoz N, Langvatn R, Stenseth NC (2005) Importance of climatological downscaling and plant phenology for red deer in heterogeneous landscapes. Proc R Soc Lond B 272:2357-2364

Quadrelli R, Lazzeri M, Cacciamani C, Tibaldi S (2001) Observed winter Alpine precipitation variability and links with large-scale circulation patterns. Clim Res 17:275-284

Rimbu N, Dima M, Lohmann G, Stefan S (2004) Impacts of the North Atlantic Oscillation and the El Niño-Southern Oscillation on Danube river flow variability. Geophys Res Lett 23:L23203, doi:10.1029/2004GL020559

Souissi S, Ginot V, Seuront L, Uye SI (2004) Using multi-agent systems to develop individual based models for copepods: consequences of individual behaviour and spatial heterogeneity on the emerging properties at the population scale. In: Seuront L, Strutton P (eds) Handbook of scaling methods in aquatic ecology: measurement, analysis, simulation. CRC Press, Boca Raton, FL, p 527-546

Stenseth NC, Otterser G, Hurrell J, Mysterud A, Lima M, Chan KS, Yoccoz N, Adlandsvik B (2003) Studying climate effects on ecology through the use of climate indices: the North Atlantic Oscillation, El Niño Southern Oscillation and beyond. Proc R Soc Lond B 270:2087-2096

Straile D, Hälbich A (2000) Life history and multiple antipredator defenses of an invertebrate pelagic predator, Bythotrephes longimanus. Ecology 81:150-163

Straile D, Livingstone DM, Weyhenmeyer GA, George DG (2003) The response of freshwater ecosystems to climate variability associated with the North Atlantic Oscillation. In: Hurrell JW, Kushnir Y, Ottersen G, Visbeck M (eds) The North Atlantic Oscillation: climatic significance and environmental impact. American Geophysical Union, Washington DC, p 263-279

Sullivan CA, Lehman JT (1998) Character variation and evidence for spine length selection in the invertebrate predator Bythotrephes (Crustacea: Cladocera) from Lakes Michigan, Huron, and Erie. Arch Hydrobiol 142:35-52

Trigo R, Osborn T, Corte-Real J (2002) The North Atlantic Oscillation influence on Europe: climate impacts and associated physical mechanisms. Clim Res 20:9-17

Vijverberg J, Koelewijn HP, van Densen WLT (2005) Effects of predation and food on the population dynamics of the raptorial cladoceran Leptodora kindtii. Limnol Oceanogr 50:45-464

Voigt W, Perner J, Davis A, Eggers T and 8 others (2003) Trophic levels are differentially sensitive to climate. Ecology 84:2444-2453

von Storch H (1995) Spatial patterns: EOF and CCAs. In: von Storch H, Navarra A (eds) Analysis of climate variability. Springer-Verlag, Berlin, p 227-253

von Storch H, Zorita E, Cubasch U (1993) Downscaling of global climate change estimates to regional scales: an application to Iberian rainfall in wintertime. J Clim 6:1161-1171

Winder M, Schindler D (2004) Climate effects on the phenology of lake processes. Global Change Biol 10:1844-1856

Wu A, Hsieh W (2004) The nonlinear association between ENSO and the Euro-Atlantic winter sea level pressure. Clim Dyn 23:859-868

Submitted: August 16, 2006; Accepted: February 7, 2007

Proofs received from author(s): April 17, 2007 